\title{
The impact of light intensity and daylength on silicate and nitrate competition among marine phytoplankton
}

\author{
Ulrich Sommer 1 \\ ICBM, Carl-von-Ossietzky Universität, P.O. Box 2503, D-26111 Oldenburg, Germany
}

\begin{abstract}
I tested the extent to which differences in light supply could influence the outcome of nutrient (Si and $\mathrm{N})$ competition between marine phytoplankton. Competition experiments were performed with 11 species of marine phytoplankton at $\mathrm{Si}: \mathrm{N}$ ratios from 16 to $124: 1$, light intensities from 28 to $225 \mu \mathrm{mol}$ quanta $\mathrm{m}^{-2} \mathbf{s}^{-1}$, and three different daylengths. Thus, light supply was the composite result of two components: photoperiod and intensity. Diatoms were dominant competitors at higher $\mathrm{Si}: \mathbf{N}$ ratios, nonsiliceous flagellates at lower ones. Light had no impact on the transition from flagellate to diatom dominance along the $\mathrm{Si}: \mathrm{N}$ gradient. However, species within those groups were separated along the light gradient. Contrary to theoretical expectations, changes in light intensity and changes in daylength led to similar shifts in species dominance. Therefore, it was possible to describe the light climate by the integral parameter "daily light dose."
\end{abstract}

Competition for limiting resources is one of several factors structuring phytoplankton communities. The theoretical and experimental analysis of resource competition gained momentum with Tilman's (1977) competition experiments with the freshwater diatoms $A s$ terionella formosa and Cyclotella meneghiniana. A largely consistent body of theory (Tilman 1982) and experimental evidence has since developed (see Sommer 1989). Tilman's theory makes two major predictions. First, at steady state only as many species can coexist as there are growth rate-limiting resources. Winners of competition (coexisting species) can be identified by zero net growth rates at steady state while losers can be identified by negative net growth rates. Second, the taxonomic identity and the relative abundances of the coexisting species depend on the ratio of the limiting resources (resource ratio hypothesis).

Most of the published experiments have used mineral nutrients as limiting resources ( $\mathrm{Si}$ and P: e.g. Tilman 1977, 1981; Sommer 1983; Kilham 1986; Si, N, and P: Tilman et al. 1986) and freshwater phytoplankton as test organisms. The resource ratio hypothesis has been used to explain seasonal species replacements

\footnotetext{
1 Present address: Institut für Meereskunde, Düsternbrooker Weg 20, D-24105 Kiel, Germany.

\section{Acknowledgments}

Technical assistance by B. Kürzel-Seidel and R. Weinert is gratefully acknowledged. The manuscript profited from reviews by D. Tilman and an anonymous reviewer.
}

within lakes (Sommer 1993), compositional differences at comparable seasons between lakes (Makulla and Sommer 1993), and longterm species replacements within one lake (Sommer et al. 1993). Also eutrophication-dependent shifts in marine phytoplankton have been explained by decreasing $\mathrm{Si}: \mathrm{N}$ or $\mathrm{Si}: \mathrm{P}$ ratios (Riegman 1991; Smayda 1989, 1990). However, species replacements of marine phytoplankton along $\mathrm{Si}: \mathrm{N}$ or $\mathrm{Si}: \mathrm{P}$ gradients have not been tested by culture competition experiments so far (except for Antarctic algac: Sommer 1986).

Contrary to nutrients, light has received little attention in published competition studies. In previous studies, light has usually been supplied at supposedly saturating intensities in order to preclude competition for light. Tilman $(1990$, p. 134) pointed out that

$$
\begin{aligned}
& \text { light competition is conceptually more complex than } \\
& \text { nutrient competition. We do not yet have either rig- } \\
& \text { orous theoretical predictions or experimental results } \\
& \text { that indicate that a single number, analogous to } R^{*} \text {, } \\
& \text { can predict the outcome of competition for light. A } \\
& \text { fuller understanding of light competition remains a } \\
& \text { major challenge. }
\end{aligned}
$$

There are at least four reasons for the higher complexity of light competition. First, several components of the light field are not subject to exploitation by phototrophic organisms and are, therefore, not a target of competition: surface irradiance, daylength, attenuation by dissolved and dead particulate matter. Second, the theory of competition assumes an even (or at least random) distribution of resources in 
space. This assumption may hold for nutrients in a well-mixed water column but it never holds for light. There is always a vertical gradient of light. Third, depending on physical conditions, phytoplankton may circulate within the light gradient or they may be stationary. Some can even actively search for a favorable position within the gradient (buoyant cyanobacteria: Walsby and Brooker 1980; large flagellates: Sommer and Gliwicz 1986). Fourth, physiological adaptation to low light intensities (Richardson et al. 1983) may decrease the intensity below which light becomes limiting, but more nutrients might be required for low light adaptation (e.g. more $\mathrm{N}$ for increased chlorophyll synthesis). Thus, nutrient competitive abilities might be influenced indirectly by light adapatation. A theory for light competition in a circulating water column is being developed (Huisman and Weissing 1994). It is considerably more complex than the theory of nutrient competition and does not lead to a prediction as simple as the resource ratio hypothesis.

The competition experiments presented here examine a different scenario. While silicate and nitrate were offered as competitive resources, light was a noncompetitive resource set externally by daylength and surface irradiance. This situation is comparable to a vertically stable water column where the light availability for phytoplankton at each depth is influenced by the overlying populations but not by the nutrient competitors within the same layer.

\section{Material and methods}

Organisms-The experimental organisms were 11 unialgal strains of marine algae from six higher taxa. Diatoms were represented by four species (Nitzschia pungens, Stephanopyxis palmeriana, Neostreptotheca sp., Lauderia borealis), dinoflagellates by Scrippsiella trochoidea, chlorophytes by Dunaliella tertiolecta, the Prymnesiophyceae by Chrysochromulina polylepis, Prymnesium parvum, and Pleurochrysis carterae, cryptophytes by Rhodomonas sp., and cyanobacteria by the picoplankter Synechococcus sp. Nitzschia was of Canadian origin (courtesy of R. Pocklington). The other strains originated from the North Sea (courtesy of M. Elbrächter). The inoculum biomass of all species was within one order of magnitude $\left(0.1-1 \times 10^{6} \mu \mathrm{m}^{3} \mathrm{ml}^{-1}\right)$.
Culture conditions - The medium was artificial seawater with a nutrient salt, trace-element, and vitamin mixture according to the $\mathrm{f} / 2$ formulation of Guillard and Ryther (1962), modified to obtain the required silicate: nitrate ratios and to avoid $P$ limitation even at the highest nitrate concentrations $(19.8 \mu \mathrm{M}$ $\mathrm{NO}_{3}{ }^{-}$vs. $2 \mu \mathrm{M}$ P). Silicate concentrations did not vary between experiments $(317 \mu \mathrm{M})$. $\mathrm{Si}$ : $\mathrm{N}$ ratios were adjusted by varying nitrate concentrations. Other nitrogen sources (e.g. ammonium) were not supplied. The stoichiometric $\mathrm{Si}: \mathrm{N}$ ratios were $16: 1,24: 1,31: 1$, $40: 1,74: 1$, and $124: 1$, respectively. The ratios reported here are based on chemical analysis (Strickland and Parsons 1968) of the media.

Cultures were maintained in 250-ml Erlenmeyer flasks and kept in suspension by a rotating shaking table. Once per day $30 \mathrm{ml}$ of culture suspension were replaced by fresh medium (semicontinuous culture) which gave a dilution rate of $0.3 \mathrm{~d}^{-1}$. The semicontinuous culture principle is a slight deviation from the assumption of perfect steady state in competition theory. Practical experience [e.g. Tilman's early experiments (Tilman 1977) and my own experiments with Antarctic phytoplankton (Sommer 1986)] has shown that it is an acceptable approximation. Semicontinuous cultures were chosen instead of more perfect chemostats because they are cheaper and easier to maintain, which made it possible to run 24 cultures at the same time.

Light was supplied by fluorescent tubes. To balance the low emission of the white tubes (Osram Biolux) in the red and blue spectral ranges, I combined them with an equal number of purple ones (Osram Fluora). Experimental light intensities were set by distance to the light source. Due to lateral heterogeneities in the light field, light intensities were not exactly identical within each row of the shaking table (Table 1). Light intensities given here are starting intensities $\left(I_{0}\right)$ measured inside culture flasks containing medium but no algae. Light absorption by algae played only a minor role because of the smallness of the cultures. Light intensities in the flasks measured at the end of each experiment were always $>0.9 I_{0}$. Three different light/dark cycles were used: $16: 8,12$ : 12 , and $8: 16 \mathrm{~h}$. The experimental temperature was $15^{\circ} \mathrm{C}$. 
Table 1. Light intensity ( $\mu \mathrm{mol}$ quanta $\mathrm{m}^{-2} \mathrm{~s}^{-1}$ PAR) and $\mathrm{Si}: \mathrm{N}\left(\mathrm{mol} \mathrm{mol}^{-1}\right)$ ratios in the experimental treatments.

\begin{tabular}{lrrrrrr}
\hline \hline & \multicolumn{6}{c}{ Si:N } \\
\cline { 2 - 7 } & $16: 1$ & $24: 1$ & $31: 1$ & $40: 1$ & $74: 1$ & $124: 1$ \\
\hline Row 1 & 142 & 197 & 223 & 225 & 216 & 199 \\
Row 2 & 72 & 83 & 94 & 100 & 105 & 99 \\
Row 3 & 36 & 38 & 46 & 55 & 55 & 60 \\
Row 4 & 28 & 28 & 33 & 37 & 39 & 40 \\
\hline
\end{tabular}

Sampling and counting-All cultures were sampled twice a week (Tuesday, Friday) and fixed with Lugol's iodine. Ten milliliters of each sample were settled in Utermöhl chambers for counting under an inverted microscope. When enough individuals were present, 100-200 individuals of each species were counted which gives a $95 \%$ C.I. of $\pm 14-20 \%$ if individuals are randomly distributed. Prymnesiophyceae were identified to species level only during the last three counts. The biomass of each species was estimated as cell volume $\left(V_{i}\right)$ which was calculated as the product of cell number (in No. $\mathrm{ml}^{-1}$ ) and mean volume of individual cells (in $\mu \mathrm{m}^{3}$ ). The latter was obtained by approximation to the nearest standard geometric solid after microscopic measurements of at least 20 individuals. The relative importance $\left(p_{i}\right)$ of a species was expressed by its contribution to total cell volume $\left(V_{i} / V_{\text {tot }}\right)$.

\section{Results}

Time-course of experiments-Initially all species increased, thus indicating at least suitable growth conditions. In nearly all experiments, Dunaliella and the prymnesiophycean flagellates had the largest initial increases. After $\sim 1$ week, the first competitive displacements began. The final species composition began to stabilize after 3-4 weeks. After 5 weeks, the experiments were terminated. At that time, one or two species in the high light treatments and one to three species in the low light treatments formed $95 \%$ of the total cell volume. Sometimes losing competitors still had countable abundances at the end of the experiments. They were classified as losers when there was a significant $(P<0.05)$ correlation between log abundance and time. The growth pattern of Dunaliella in Fig. 1 is one such example. In the following, I will use two different

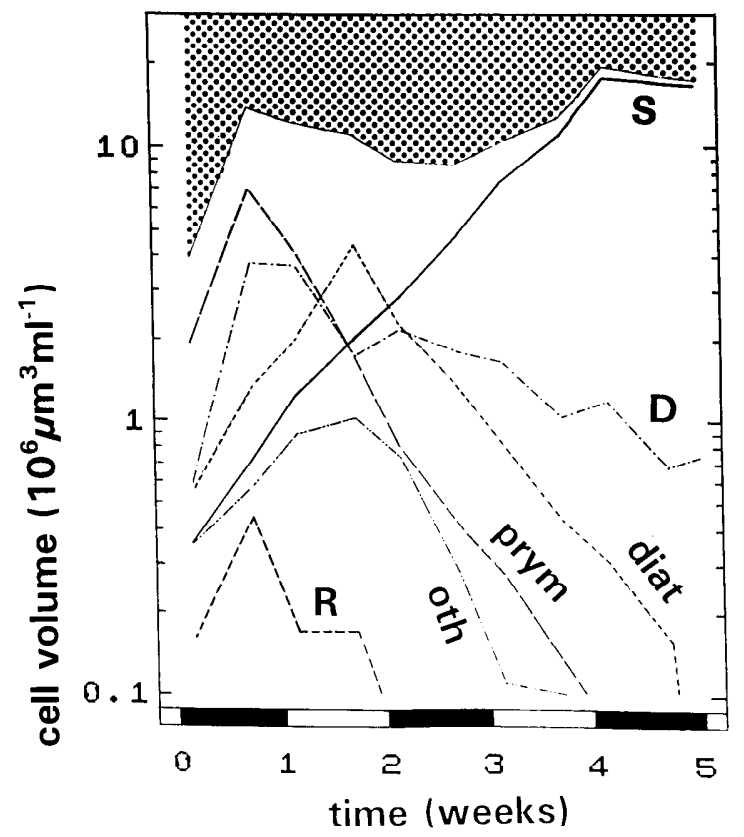

Fig. 1. Example for the time-course of competition experiments. Experiment at $\mathrm{Si}: \mathrm{N} 74: 1, I=216 \mu \mathrm{mol}$ quanta $\mathrm{m}^{-2} \mathrm{~s}^{-1}, \mathrm{~L} / \mathrm{D}$ cycle $16: 8$. Total cell volume: white area below shading; $\mathbf{S}-$ Stephanopyxis palmeriana; diatother diatoms; D-Dunaliella tertiolecta; $R-R$ hodomonas sp.; prym-Prymnesiophyceae; oth-other species.

expressions for species composition. The term "final species composition" describes the species composition at the end of an experiment without consideration of winners and losers. The term "equilibrium species composition" is a forecast based on the assumptions that the losers will eventually decline to zero while the biomass ratios between the winners will remain unchanged. The more descriptive Figs. 2-7 are based on "final species composition"; the regression analysis in Table 2 and Fig. 8 are based on "equilibrium species composition."

Only six species ever contributed $>10 \%$ to final biomass: $S$. palmeriana, $L$. borealis, $N$. pungens, D. tertiolecta, C. polylepis, and Rhodomonas sp. These were the same species that were classified as winners in at least one experiment.

Diatoms and the Si: $N$ ratio-The contribution of diatoms to total cell volume responded only to $\mathrm{Si}: \mathrm{N}$ ratio, not to daylength or light intensity (Eq. 1 in Table 2). There was a sharp transition between $\mathrm{Si}: \mathrm{N} \mathrm{16:1}$ and $\mathrm{Si}$ : 


\section{STEPHANOPYXIS}

$L: D=16: 8$
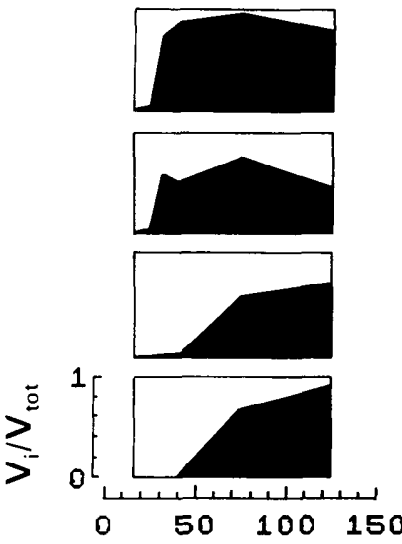

12:12
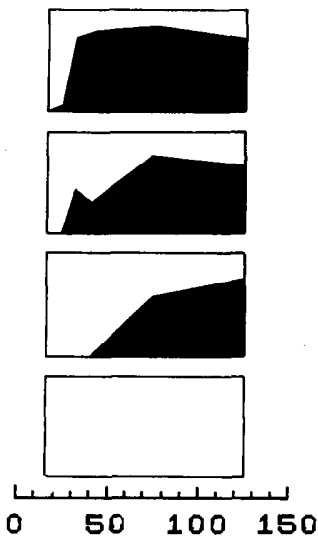

8:16

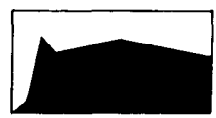

R1

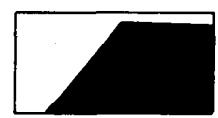

R2

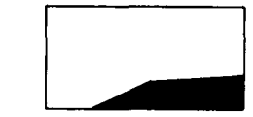

R3

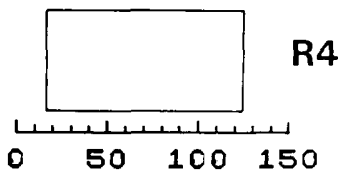

\section{Si:N ratio $(\mathrm{mol} / \mathrm{mol})$}

Fig. 2. Contribution of Stephanopyxis palmeriana to total cell volume (black area) at the end of competition

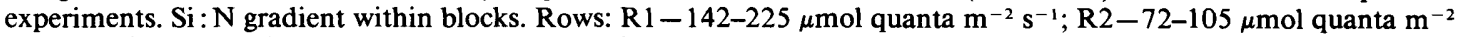
$\mathrm{s}^{-1} ; \mathrm{R} 3-36-60 \mu \mathrm{mol}$ quanta $\mathrm{m}^{-2} \mathrm{~s}^{-1} ; \mathrm{R} 4-28-40 \mu \mathrm{mol}$ quanta $\mathrm{m}^{-2} \mathrm{~s}^{-1}$.

$\mathrm{N} 31: 1$. At ratios $>31: 1$ only diatoms were classified as winners. At ratios $<16: 1$ no diatom species could persist. At $31: 1$ diatoms contributed $60-90 \%$ to equilibrium biomass; at $24: 1$ they contributed $<40 \%$.

Final species composition-S. palmeriana was the dominant alga at high $\mathrm{Si}: \mathrm{N}$ ratios and high light conditions (Fig. 2). Both reduction of light intensity and daylength decreased its importance relative to other diatoms. At 12and 8-h daylength, it was completely excluded from cultures with light intensities $<40 \mu \mathrm{mol}$ quanta $\mathrm{m}^{-2} \mathrm{~s}^{-1}$. L. borealis was excluded from the highest $\left(>150 \mu \mathrm{mol}\right.$ quanta $\mathrm{m}^{-2} \mathrm{~s}^{-1}, 16-\mathrm{h}$ daylength) and from the lowest ( $<40 \mu \mathrm{mol}$ quanta $\mathrm{m}^{-2} \mathrm{~s}^{-1}, 8-\mathrm{h}$ daylength) light conditions. The competitive optimum of this species was a combination of medium $\mathrm{Si}: \mathrm{N}(40$ : 1) and medium amount of light (Fig. 3). $N$. pungens was absent or nearly absent from high light cultures, but it was the dominant phytoplankton species at high $\mathrm{Si}: \mathrm{N}$ and low light conditions (Fig. 4).

Among the nonsilicified taxa, there was a segregation of species along the light gradient. The green alga $D$. tertiolecta was dominant at low $\mathrm{Si}: \mathrm{N}$ at light intensities $>70 \mu \mathrm{mol}$ quanta $\mathrm{m}^{-2} \mathrm{~s}^{-1}$ under long and medium daylength (Fig. 5). Decreasing light intensity and decreas- ing daylength led to a decreased importance of Dunaliella. C. polylepis appeared to be the specialist for medium light among the flagellates (Fig. 6), while Rhodomonas was the dominant flagellate under low light conditions (Fig. 7).

\section{Discussion}

Nutrient ratios - The general pattern of increasing importance of diatoms with increasing $\mathrm{Si}: \mathrm{N}$ ratios resembles a similar pattern

Table 2. Multiple regression analysis (stepwise variable selection, backward procedure, $F$-to-remove $=4$ ) of relative contribution to biomass $\left(p_{i}\right)$ on $\mathrm{Si}: \mathrm{N}$ ratios and daily light dose. $y=\arcsin p_{i} ; x=\log _{10}(\mathrm{Si}: \mathrm{N}) ; z=\log _{10}$ DLD. All regressions are significant at $P<0.0001$.

(Eq. 1) All diatoms: $y=-1.95+1.85 x, r^{2}=0.71$

(Eq. 2) Stephanopyxis: $\mathrm{y}=-1.48+1.04 x+0.81 z^{2}, r^{2}$ $=0.69$;

(Eq. 3) Lauderia: $y=-6.43+7.76 x-2.24 x^{2}+1.64 z$ $-1.56 z^{2}, r^{2}=0.44$

(Eq. 4) Nitzschia: $y=-3.51+4.93 x-1.34 x^{2}-1.81 z$ $+0.90 z^{2}, r^{2}=0.43$;

(Eq. 5) Dunaliella: $y=5.30-5.71 x+1.40 x^{2}+1.44 z$ $-0.80 z^{2}, r^{2}=0.49$

(Eq. 6) Chrysochromulina: $y=5.20-5.64 x+1.53 x^{2}$ $-0.19 z^{2}, r^{2}=0.44$;

(Eq. 7) Rhodomonas: $y=0.86-0.33 x-0.43 z$, $r^{2}=0.40$. 


\section{LAUDERIA}

$L: D=16: 8$
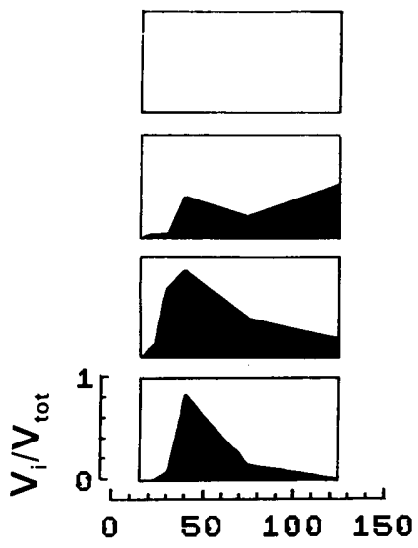

12:12
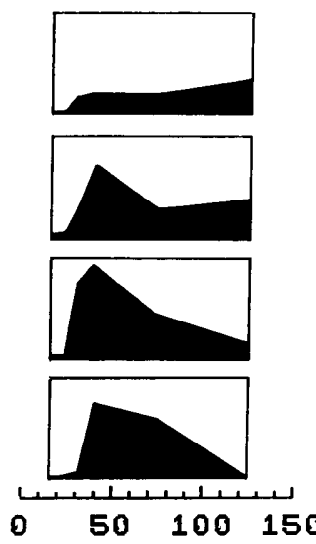

8:16

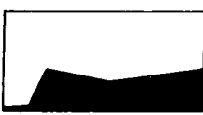

R1

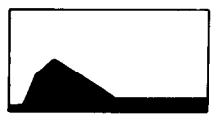

R2

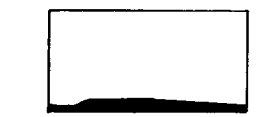

R3

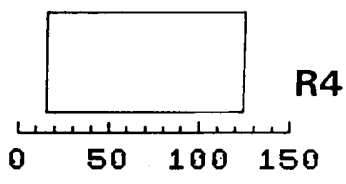

R4

\section{Si:N ratio $(\mathrm{mol} / \mathrm{mol})$}

Fig. 3. As Fig. 2, but of Lauderia borealis.

observed along the Si : P gradient in lake phytoplankton (Sommer 1983; Kilham 1986; Tilman et al. 1986). The $\mathrm{Si}: \mathrm{N}$ ratio has received less attention in freshwater ecology because conventional (but not rigorously tested) wisdom (Hecky and Kilham 1988) considers N limitation in lakes unimportant.

The increase of flagellates with decreasing
$\mathrm{Si}: \mathrm{N}$ ratios in my experiment seems consistent with Smayda's $(1989,1990)$ and Riegman's (1991) hypothetical explanation of species shifts in eutrophicated coastal waters. The agreement, however, is only qualitative; at the quantitative level, a major discrepancy remains. In my experiments, the transition took place at much higher ratios (between 16 and

\section{NITZSCHIA}

\section{$L: D=16: 8$}

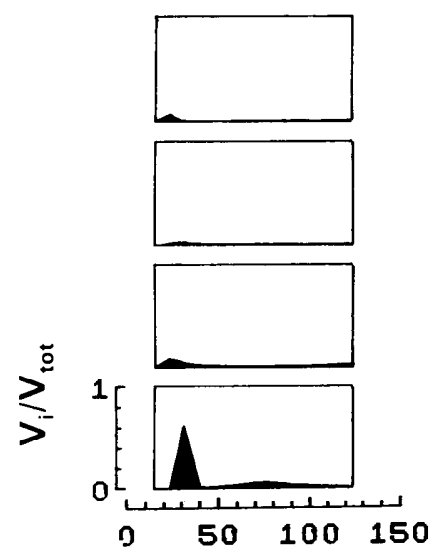

12:12
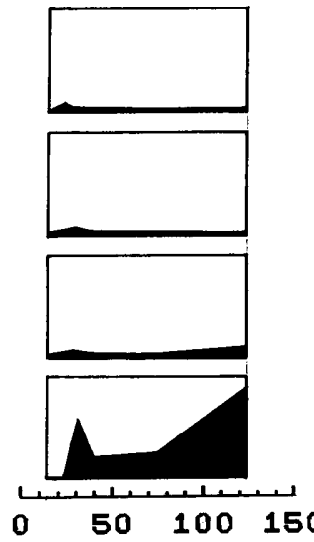

8:16

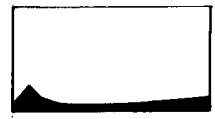

R1

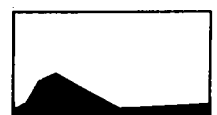

R2

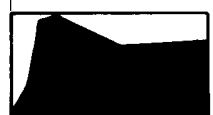

R3

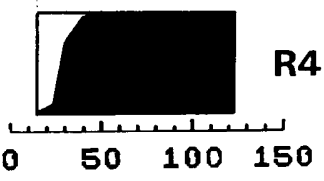

\section{Si:N ratio $(\mathrm{mol} / \mathrm{mol})$}

Fig. 4. As Fig. 2, but of Nitzschia pungens. 


\section{DUNALIELLA}

$L: D=16: 8$
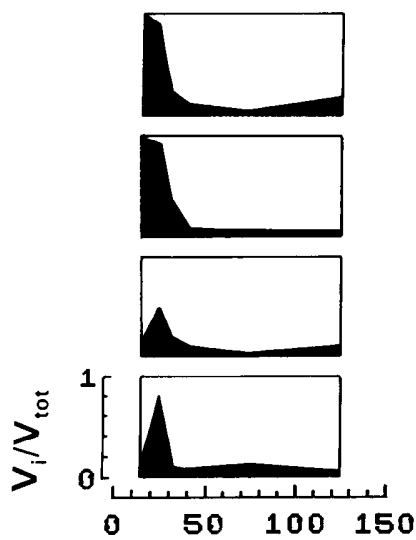

12:12
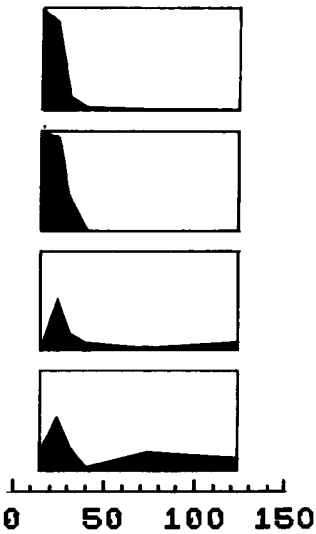

Si:N ratio (mol $/ \mathrm{mol})$
8:16

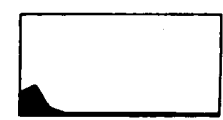

R1

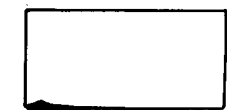

R2

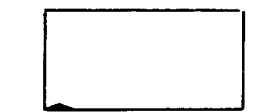

R3

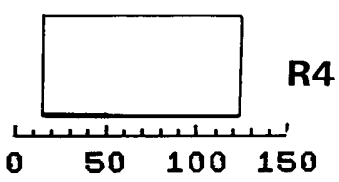

R4

Fig. 5. As Fig. 2, but of Dunaliella tertiolecta.

$31: 1)$ than in eutrophicated coastal seas, such as the southern North Sea, where diatom dominance, usually observed in spring, is being partially replaced by flagellates (Cadée 1986; Cadée and Hegeman 1991; Riegman et al. 1992). In the southern North Sea, winter (prebloom) $\mathrm{Si}: \mathrm{N}$ was between 1 and $2: 1$ during the 1960s and has decreased because of increased $\mathrm{N}$ loading to $0.1-0.25$ at present (Radach et al. 1990).

There are several possible explanations for this discrepancy. Nanoplankton flagellates are subject to higher grazing losses than diatoms. The higher loss rates might compress the com-

\section{CHRYSOCHROMULINA}

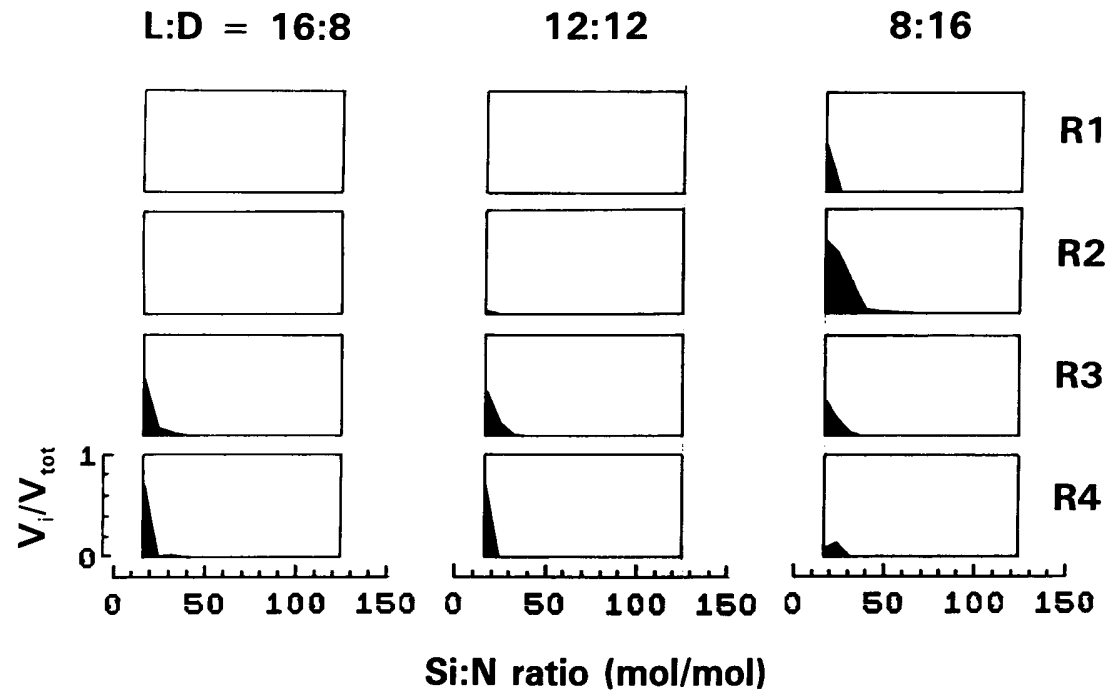

Fig. 6. As Fig. 2, but of Chrysochromulina polylepis. 


\section{RHODOMONAS}

$L: D=16: 8$

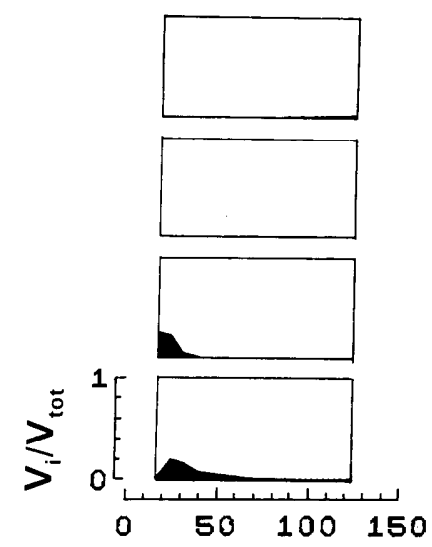

12:12

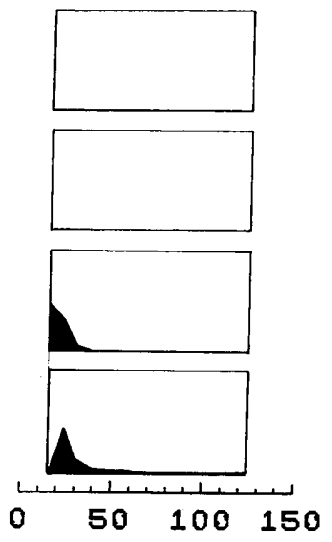

8:16

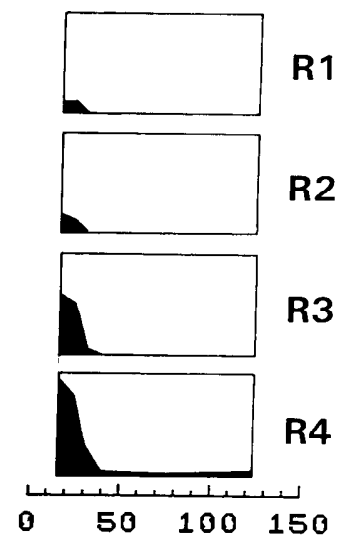

Si:N ratio $(\mathrm{mol} / \mathrm{mol})$

Fig. 7. As Fig. 2, but of Rhodomonas sp.

petitive niche of flagellates along the $\mathrm{Si}$ : $\mathrm{N}$ gradient. Environmental variability in situ (e.g. vertical transport through the light gradient) might displace the $\mathrm{Si}: \mathrm{N}$ ratio of dominance transitions relative to cultures with constant conditions. Such displacements have been found experimentally at several levels of environmental complexity (periodic nutrient supply: Sommer 1985; addition of grazers and nutrient recycling: Sommer 1988). The diatoms used in my experiments have unusually high $\mathrm{Si}$ requirements. At present, I consider this explanation most plausible. In a series of ongoing experiments (Sommer unpubl.) in a different context, some diatoms (e.g. Nitzschia closterium, Asterionella glacialis) win competition against flagellates at any $\mathrm{Si}: \mathrm{N}>2: 1$.

Light field-It is obvious from Figs. 2 to 7 that daylength and light intensities had qualitatively similar impacts on the performance of species along the $\mathrm{Si}: \mathrm{N}$ gradient. No species preferred the combinations of long day-dim light or short day-bright light. This finding leads to the question of whether the two dimensions of the light niche in the experimental design can be combined into one: daily light dose (DLD) calculated as the product of light intensity $(I)$ times the length of the light period $(L)$. Theoretically, this should be incorrect be- cause of the nonlinear response of growth rate to light intensity. Under light saturation, no increase in intensity could compensate for a decrease in photoperiod. There is no simple way to calculate a "corrected light dose" where light intensity is substituted by a value which takes saturation into account (e.g. by truncating all light intensities at the saturation coefficient). Different species have different saturation curves. Therefore, a particular combination of $I$ and $L$ in one culture could result in a different corrected light dose for different species.

In spite of these theoretical objections, even coarser general indices of light (e.g. the ratio of euphotic depth to mixing depths) have made an acceptable practical compromise in describing the light niche of phytoplankton species in situ (e.g. Reynolds and Reynolds 1985). Therefore, I tried to examine the utility of DLD by a multiple regression analysis (stepwise variable selection, backward procedure, $F$-toremove 4.0 ). The arcsin-square-root-transformed $p_{i}$ values based on equilibrium species composition were entered as the dependent variable. The independent variables were $\log _{10}(\mathrm{Si}: \mathrm{N}), \log _{10} \mathrm{DLD}$, and the squares of both (Table 2) or, alternatively, $\log _{10} I$ and $\log _{10} L$ and the squares of both instead of $\log _{10}$ DLD. 


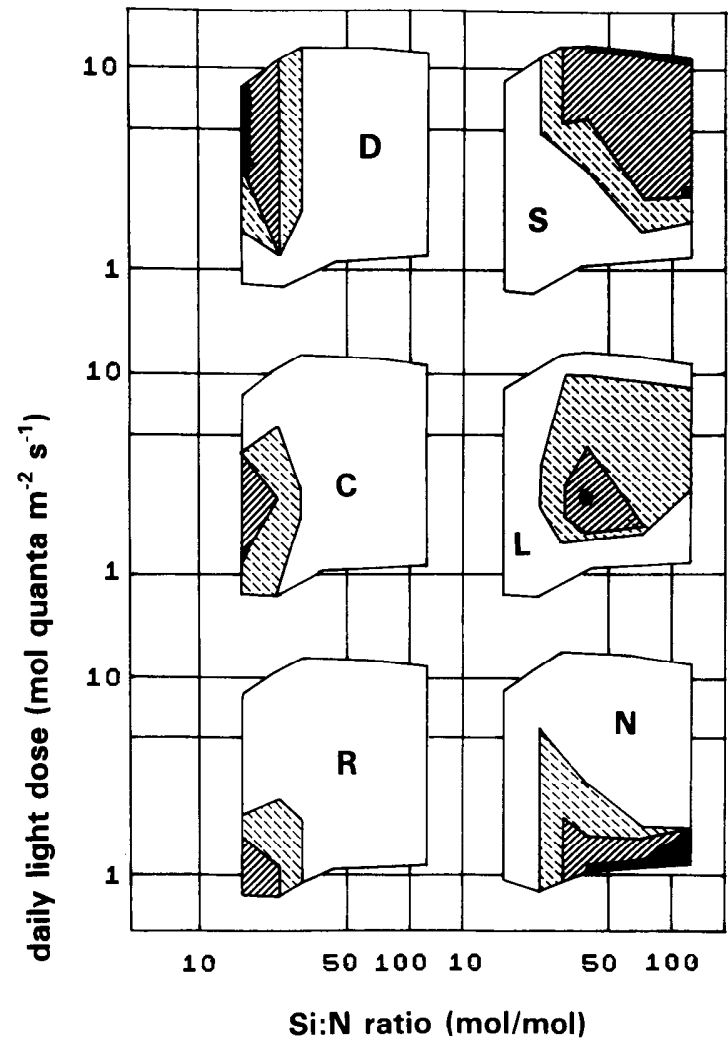

Fig. 8. Contour diagrams of the competitive success of Dunaliella tertiolecta (D), Chrysochromulina polylepis (C), Rhodomonas sp. (R), Stephanopyxis palmeriana (S), Lauderia borealis (L), and Nitzschia pungens at different $\mathrm{Si}: \mathrm{N}$ ratios and daily light doses; white-excluded; broken hatching-persisting, but $<50 \%$ of equilibrium cell volume; hatching $->50 \%$; black $-100 \%$.

Using light intensity and daylength separately instead of DLD did not significantly improve the goodness-of-fit; $r^{2}$-values never increased by more than 0.03 .

Having thus established that the use of DLD as a considerable simplification without a significant deterioration of fit, I constructed the contour diagrams in Fig. 8. The contours are based on the original data for equilibrium species composition and not on the regression equations. They are a graphical representation of the competitive niche of each of the six species under discussion with the dimensions $\mathrm{Si}: \mathrm{N}$ ratio and DLD.

Further experimentation with more species and a wider range of light intensities is needed to test the robustness of the daily light dose concept. A considerable reduction of light cli- mate complexity would be possible if light variability in the vertical gradient could also be integrated into DLD. On the other hand, I expect that light inhibition at high intensities would strongly restrict the usefulness of DLD.

\section{References}

CADÉE, G. C. 1986. Recurrent and changing seasonal patterns of phytoplankton in the westernmost inlet of the Wadden Sea, the Marsdiep since 1973, p. 105112. In CEC Water Pollut. Res. Rep. 12.

- AND J. HegemaN. 1991. Historical phytoplankton data for the Marsdiep. Hydrobiol. Bull. 24: 111 119.

Guillard, R. R. L., AND J. H. RYther. 1962. Studies on marine diatoms. 1. Cyclotella nana Hustedt and Detonula confervacea Gran. Can. J. Microbiol. 8: 229239.

HeCKY, R. E., AND P. KILHAM. 1988. Nutrient limitation of phytoplankton in freshwater and marine environments: A review of recent evidence of the effects of enrichment. Limnol. Oceanogr. 33: 786-822.

Huisman, J., AND F. J. WeISSING. 1994. Light-limited growth and competition for light in well-mixed aquatic environments: An elementary model. Ecology 75: 507-520.

KILHAM, S. S. 1986. Dynamics of Lake Michigan phytoplankton communities in continuous cultures along a Si : P loading gradient. Can. J. Fish. Aquat. Sci. 43: 351-360.

MAKulla, A., AND U. Sommer. 1993. Relationships between resource ratios and phytoplankton species composition during spring in five north German lakes. Limnol. Oceanogr. 38: 846-856.

RADACH, G., J. Berg, AND E. HAGMeIER. 1990. Longterm changes of the annual cycles of meteorological, hydrographic, nutrient and phytoplankton time series at Helgoland and at LV ELBE 1 in the German Bight. Cont. Shelf Res. 10: 305-328.

ReYNolds, C. S., AND J. B. ReYNolds. 1985. The atypical seasonality of phytoplankton in Crose Mere, 1972: An independent test of the hypothesis that variability in the physical environment regulates community dynamics and structure. Br. Phycol. J. 20: 227-242.

Richardson, K., J. BeARDAll, AND J. A. RAVEN. 1983. Adaptation of unicellular algae to irradiance; an analysis of strategies. New Phytol. 93: 157-191.

RIEGMAN, R. 1991. Mechanisms behind eutrophicationinduced novel algal blooms. Neth. Inst. Sea Res. Rapp. 9: $1-51$.

- A. A. M. Noordeloos, and G. C. Cadée. 1992. Phaeocystis blooms and eutrophication of the continental coastal zones of the North Sea. Mar. Biol. 112: $479-484$.

SMAYDA, T. J. 1989. Primary production and the global epidemic of phytoplankton blooms in the sea: A linkage?, p. 449-483. In E. M. Cosper et al. [eds.], Novel phytoplankton blooms. Springer.

. 1990. Novel and nuisance phytoplankton blooms in the sea: Evidence for a global epidemic, p. 29-41. In E. Granéli et al. [eds.], Toxic marine phytoplankton. Elsevier. 
SOMMER, U. 1983. Nutrient competition between phytoplankton in multispecies chemostat experiments. Arch. Hydrobiol. 96: 399-416.

. 1985. Comparison between steady state and nonsteady state competition: Experiments with natural phytoplankton. Limnol. Oceanogr. 30: 335-346.

- 1986. Nitrate- and silicate-competition among Antarctic phytoplankton. Mar. Biol. 91: 345-351.

- 1988. Phytoplankton succession in microcosm experiments under simultaneous grazing pressure and resource limitation. Limnol. Oceanogr. 33: 1037-1054. - 1989. The role of competition for resources in phytoplankton species succession, p. 57-106. In U. Sommer [ed.], Plankton ecology-succession in plankton communities. Springer.

- 1993. Phytoplankton competition in Plußsee: $\mathbf{A}$ field test of the resource ratio hypothesis. Limnol. Oceanogr. 38: 838-845.

, U. GAEDKE, AND A. SCHWEizer. 1993. The first decade of oligotrophication of Lake Constance. 2. The response of phytoplankton taxonomic composition. Oecologia 93: 276-284.

, AND Z. M. GLIWICZ. 1986. Long range vertical migration of Volvox in tropical Lake Cahora Bassa (Mozambique). Limnol. Oceanogr. 31: 650-653.

Strickland, J. D. H., AND T. R. Parsons. 1968. A practical handbook of seawater analysis. Bull. Fish. Res. Bd. Can. 169.

TILMAN, D. 1977. Resource competition between planktonic algae: An experimental and theorctical approach. Ecology 58: 338-348.

. 1981. Test of resource competition theory using four species of Lake Michigan algae. Ecology 62: 802815.

- 1982. Resource competition and community structure. Princeton.

- 1990. Mechanisms of plant competition for nutrient: The elements of a predictive theory of competition, p. 117-141. In J. B. Grace and D. Tilman [eds.], Perspectives on plant competition. Academic.

$\longrightarrow$, R. Kiesling, R. Sterner, S. S. KIIHAM, AND F. A. Johnson. 1986. Green, bluegreen and diatom algae: Taxonomic differences in competitive ability of phosphorus, silicon and nitrogen. Arch. Hydrobiol. 106: 473-485.

Walsby, A. E., AND M. J. BroOKer. 1980. Changes in buoyancy of a planktonic blue-green alga in response to light intensity. Br. Phycol. J. 15: 311-319.

Submitted: 23 March 1994 Accepted: 11 May 1994 Amended: 14 July 1994 